\title{
Article \\ Small RNA F6 Provides Mycobacterium smegmatis Entry into Dormancy
}

\author{
Artem Grigorov ${ }^{1,+}$, Oksana Bychenko ${ }^{1,+}{ }^{,}$Elena G. Salina ${ }^{2,+} \oplus$, Yulia Skvortsova ${ }^{1}$, Arina Mazurova ${ }^{1}$, \\ Timofey Skvortsov ${ }^{3}$ (i), Arseny Kaprelyants ${ }^{2}$ and Tatyana Azhikina ${ }^{1, *(1)}$ \\ 1 Shemyakin-Ovchinnikov Institute of Bioorganic Chemistry, Russian Academy of Sciences, \\ 117997 Moscow, Russia; artgrigorov@gmail.com (A.G.); oksana.belonovich@gmail.com (O.B.); \\ ju.skvortsova@gmail.com (Y.S.); mazarina@yandex.ru (A.M.) \\ 2 Research Center of Biotechnology, Bach Institute of Biochemistry, 119071 Moscow, Russia; \\ elenasalina@yandex.ru (E.G.S.); arseny@inbi.ras.ru (A.K.) \\ 3 School of Pharmacy, Queen's University Belfast, Belfast BT9 7BL, UK; t.skvortsov@qub.ac.uk \\ * Correspondence: tatazhik@ibch.ru; Tel.: +7-495-330-6992 \\ + These authors equally contributed to the work.
}

\section{check for} updates

Citation: Grigorov, A.; Bychenko, O.; Salina, E.G.; Skvortsova, Y.;

Mazurova, A.; Skvortsov, T.;

Kaprelyants, A.; Azhikina, T. Small RNA F6 Provides Mycobacterium smegmatis Entry into Dormancy. Int. J Mol. Sci. 2021, 22, 11536. https:// doi.org/10.3390/ijms222111536

Academic Editors: Alicja Wegrzyn, Sylwia Bloch and

Monika Maciag-Dorszynska

Received: 17 September 2021

Accepted: 22 October 2021

Published: 26 October 2021

Publisher's Note: MDPI stays neutral with regard to jurisdictional claims in published maps and institutional affiliations.

Copyright: (C) 2021 by the authors. Licensee MDPI, Basel, Switzerland. This article is an open access article distributed under the terms and conditions of the Creative Commons Attribution (CC BY) license (https:// creativecommons.org/licenses/by/ $4.0 /)$.

\begin{abstract}
Regulatory small non-coding RNAs play a significant role in bacterial adaptation to changing environmental conditions. Various stresses such as hypoxia and nutrient starvation cause a reduction in the metabolic activity of Mycobacterium smegmatis, leading to entry into dormancy. We investigated the functional role of F6, a small RNA of M. smegmatis, and constructed an F6 deletion strain of M. smegmatis. Using the RNA-seq approach, we demonstrated that gene expression changes that accompany F6 deletion contributed to bacterial resistance against oxidative stress. We also found that F6 directly interacted with 5'-UTR of MSMEG_4640 mRNA encoding RpfE2, a resuscitationpromoting factor, which led to the downregulation of RpfE2 expression. The F6 deletion strain was characterized by the reduced ability to enter into dormancy (non-culturability) in the potassium deficiency model compared to the wild-type strain, indicating that F6 significantly contributes to bacterial adaptation to non-optimal growth conditions.
\end{abstract}

Keywords: Mycobacterium smegmatis; small non-coding RNA; F6; resuscitation promoting factor RpfE2; dormancy; non-culturability; adaptation to stresses

\section{Introduction}

Bacteria are exposed to various stresses during their lifetime and, in order to adapt and survive, they have to rapidly modify their gene expression. To achieve this, bacteria employ small regulatory RNAs (sRNAs), which post-transcriptionally regulate bacterial gene expression and provide rapid responses to changes in environmental conditions such as nutrient deprivation, stresses, or host responses [1-3]. Recent evidence shows that sRNAs act as signal transducers of environmental cues, participate in regulatory networks, and precisely coordinate gene expression in many adaptation processes by controlling mRNA transcription, translation, and stability [2]. These diverse functions are performed through various mechanisms, including RNA conformational changes, interaction with proteins, and complementary interactions with other RNA or DNA molecules.

In mycobacteria, sRNAs have been identified relatively recently [4], which can be attributed to mycobacterial physiology, as well as the absence of Hfq or other chaperones. Recent technical advances, including high throughput sequencing and computer algorithms, have enabled the identification of dozens of sRNAs in mycobacteria [5-9]. To date, sRNAs have been detected and mapped in several mycobacterial species, including Mycobacterium tuberculosis, M. bovis, M. smegmatis, M. marinum, and M. avium [6], and a significant number of them has been confirmed experimentally [10-12]. However, the regulatory mechanism is established for only a few mycobacteria (reviewed in $[7,8]$ ). 
SRNA F6 (ncRv10243, MTS194, MTB000051) was discovered in M. tuberculosis by sequencing of the low molecular mass RNA fraction and confirmed by Northern blotting [4]. F6 was found to be conserved in many species of the genus Mycobacterium, both pathogenic slow-growing and non-pathogenic fast-growing. In M. tuberculosis, the upregulation of $\mathrm{F} 6$ expression was detected under oxidative stress, hypoxia, low $\mathrm{pH}$ conditions, and macrophage infection, but the strongest upregulation was observed with nutrient deficiency [4,13]. The overexpression of F6 suppressed the growth of M. tuberculosis cells; however, neither overexpression nor deletion of the F6 gene affected the growth of M. smegmatis cells [4]. The deletion of F6 prevented the transition of M. tuberculosis from the dormant state in the Wayne hypoxia model [13]. The function of F6 under starvation has been elucidated in a recent study, which shows that F6 activates the expression of Rv0440 (groEL2) and Rv3418c (groES).

In this study, we examined the functional role of F6 in M. smegmatis, a free-living non-pathogenic bacterium. M. smegmatis has $79 \%$ nucleotide sequence identity with $M$. tuberculosis and is similar to it in terms of cell wall composition and metabolism [14], but differs significantly in lifestyle. By using a combination of bioinformatic target prediction and RNA-seq of the F6 knockout $(\triangle \mathrm{F} 6)$ strain, we found that the only candidate target was MSMEG_4640. F6 directly interacted with the 5'-UTR of MSMEG_4640 mRNA, decreasing the amount of the encoded protein, RpfE2, which belongs to the resuscitationpromoting factor (Rpf) family. Proteins of the Rpf family are hydrolytic enzymes that, similar to lysozyme and lytic transglycosylases, can cleave $1 \rightarrow 4$ glycosidic bonds between $\mathrm{N}$-acetylglucosamine and $\mathrm{N}$-acetyl (glycolyl) muramic acid of bacterial peptidoglycan [15] Being non-essential for the active growth of $M$. tuberculosis, Rpfs determine the transition of dormant forms to the active state both in vitro [16] and in vivo [17]. Here, we showed that in the in vitro model of M. smegmatis dormancy and "non-culturability" under potassium-limiting conditions [18], the $\Delta \mathrm{F} 6$ strain, in contrast to the wild-type (wt) strain, demonstrated the ability to remain culturable under stress. These results indicate the involvement of RpfE2 and F6 sRNA in the transition of M. smegmatis to dormancy under non-optimal growth conditions, suggesting distinct functional roles of F6 in M. smegmatis and M. tuberculosis.

\section{Results}

\subsection{Deletion of F6 Does Not Affect Bacterial Growth}

To obtain the unmarked F6 knockout strain $(\Delta \mathrm{F} 6)$ of M. smegmatis, we employed the p2NIL/pGOAL allele replacement procedure widely used in genetic engineering of mycobacteria $[19,20]$. The scheme is shown in Supplementary Figure S1. The homologous regions flanking the F6 gene (left, 416,281-417,720 bp and right, 417,885-419,360 bp according to the M. smegmatis genome [GenBank accession number NC_008596.1]) were amplified and cloned into the p2NIL vector. The two-step strategy was based on kanamycin, hygromycin, and X-gal selection at the plasmid integration stage with subsequent sucrose and $\mathrm{X}$-gal selection to produce double crossovers. The resulting clones were checked by PCR for the absence of the F6 gene (Supplementary Figure S1). Sanger sequencing of these PCR products confirmed F6 deletion in the region of 417,720-417,885 bp. To determine whether F6 deletion affected the $M$. smegmatis phenotype, the growth of the wt and $\Delta \mathrm{F} 6$ strains was compared in Sauton's medium supplemented with ADC and Tween- 80 (Figure 1A). The results indicated that there were no obvious differences in the growth of the two strains. Light microscopy analysis revealed that in the early logarithmic phase, $\Delta \mathrm{F} 6$ cells were prone to aggregation (Figure 1B), which may indicate that the deletion of F6 altered the cell wall composition of M. smegmatis. The aggregation disappeared with the growth of cell cultures. 
A

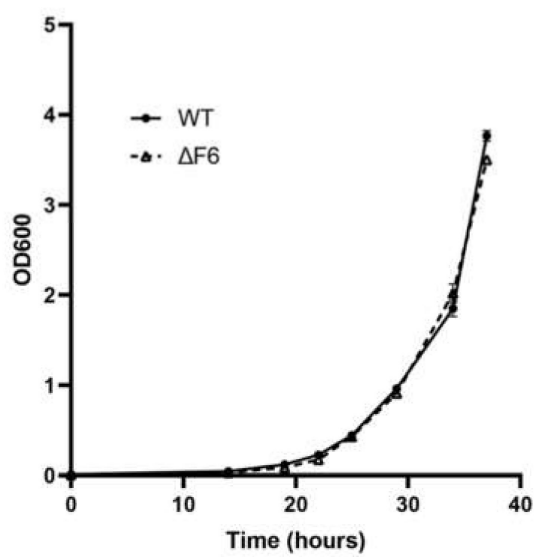

B

WT
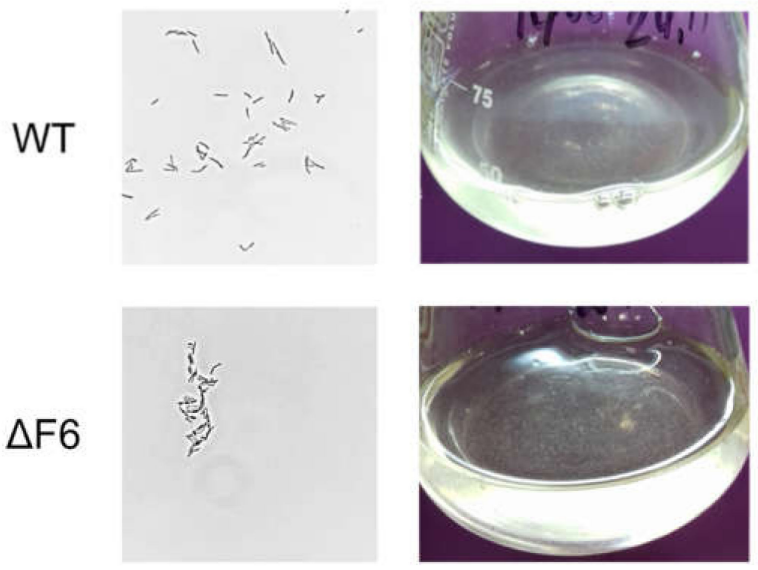

Figure 1. (A) Growth curves of M. smegmatis wt and $\Delta \mathrm{F} 6$ in Sauton's medium supplemented with $0.05 \%(v / v)$ Tween 80 . The data are presented as the mean \pm SD of three independent experiments. (B) Light microscopy image of wt and $\Delta \mathrm{F} 6$ M. smegmatis cells in the early-log phase; magnification $\times 1250$ (left panels) and the image of wt and $\Delta \mathrm{F} 6$ cultures growing in liquid media (right panels).

\subsection{F6 Deletion Affects Gene Expression in M. smegmatis}

To examine the differences in gene expression caused by F6 deletion, we performed transcriptome sequencing of the wt and $\Delta \mathrm{F} 6$ strains in the mid-log growth phase. Earlier, it had been demonstrated that F6 is highly expressed in the logarithmic growth phase both in M. tuberculosis [4] and M. smegmatis (our unpublished data). The sequencing reads were mapped against the reference genome (GenBank accession number NC_008596) and the details of mapping are given in Supplementary Table S1. Overall, 15 genes were found to be differentially expressed (FC $\geq 4, p<0.05$ ), all of which were upregulated in the $\Delta \mathrm{F} 6$ strain (Figure 2A). The list of differentially expressed genes (DEGs) is given in Table 1.

Table 1. Genes differentially expressed in the $\Delta \mathrm{F} 6$ strain compared to the wt.

\begin{tabular}{|c|c|c|c|}
\hline Gene & Product & Symbol & Fold Change \\
\hline MSMEG_0149 & Thiamine biosynthesis protein (ThiC) & & 27.3 \\
\hline MSMEG_0150 & NAD $(\mathrm{P})$ transhydrogenase subunit beta & & 29.2 \\
\hline MSMEG_0151 & PntAB protein & & 39.4 \\
\hline MSMEG_0152 & Alanine dehydrogenase & & 24.3 \\
\hline MSMEG_0153 & 2-Dehydropantoate 2-reductase & panE & 16.3 \\
\hline MSMEG_0154 & Pyruvate kinase & pyk & 16.9 \\
\hline MSMEG_0156 & LysR family transcriptional regulator & & 14.5 \\
\hline MSMEG_0157 & Oxalyl-CoA decarboxylase & & 54.1 \\
\hline MSMEG_0158 & Formyl-coenzyme A transferase & & 45.5 \\
\hline MSMEG_0159 & Formate dehydrogenase subunit gamma & & 29.8 \\
\hline MSMEG_0160 & Formate dehydrogenase subunit beta & & 38.5 \\
\hline MSMEG_0161 & Formate dehydrogenase subunit alpha & & 35.6 \\
\hline MSMEG_0162 & NAD-dependent formate dehydrogenase subunit delta & & 30.3 \\
\hline MSMEG_0168 & Formyl-coenzyme A transferase & & 19.3 \\
\hline MSMEG_4640 & Hypothetical protein & & 14.2 \\
\hline
\end{tabular}

Two large gene clusters could be distinguished (Figure 2B). The first cluster (MSMEG_156162) comprised seven genes, which were upregulated by more than 30 -fold in the $\Delta \mathrm{F} 6$ strain and the majority of which (MSMEG_0158-MSMEG_0162) encoded enzymes of formate metabolism. MSMEG_0157 is responsible for the utilization of oxalate, a toxic substance incorporated in the energy metabolism of some bacteria. In M. tuberculosis, the MSMEG_0157 homologue is essential for bacterial growth [21]. 
Another gene in this cluster was MSMEG_0156, encoding a transcription factor of the LysR family. The homologue of this gene in M. tuberculosis is OxyS, involved in the regulation of responses to oxidative stress by decreasing the expression of $k a t G$ and ahpC genes coding for catalase-peroxidase and alkyl hydroperoxide reductase, respectively; therefore, the upregulation of this transcription factor makes bacteria more sensitive to peroxides [22].

The second upregulated cluster consisted of MSMEG_0149-MSMEG_0152 and included proton-translocating $\mathrm{NAD}(\mathrm{P})(+)$ transhydrogenase PntAB (MSMEG_0151), which functions as a proton pump across the membrane and plays a role in the adaptation of bacteria to acid/oxidative stress [23].

A

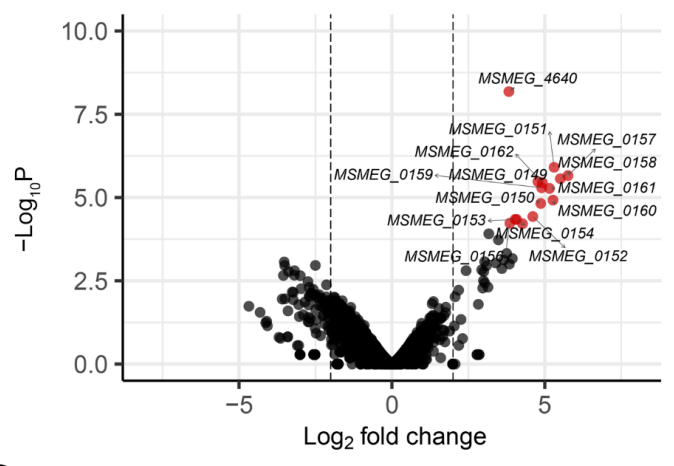

C

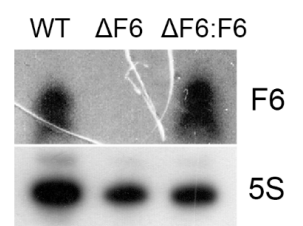

B

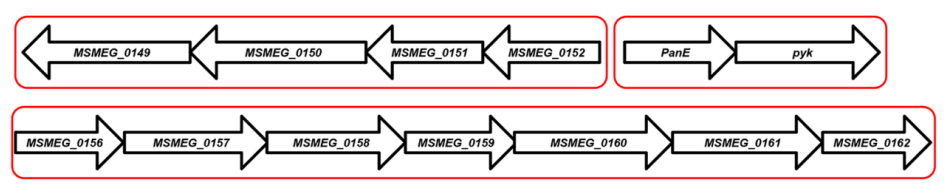

D
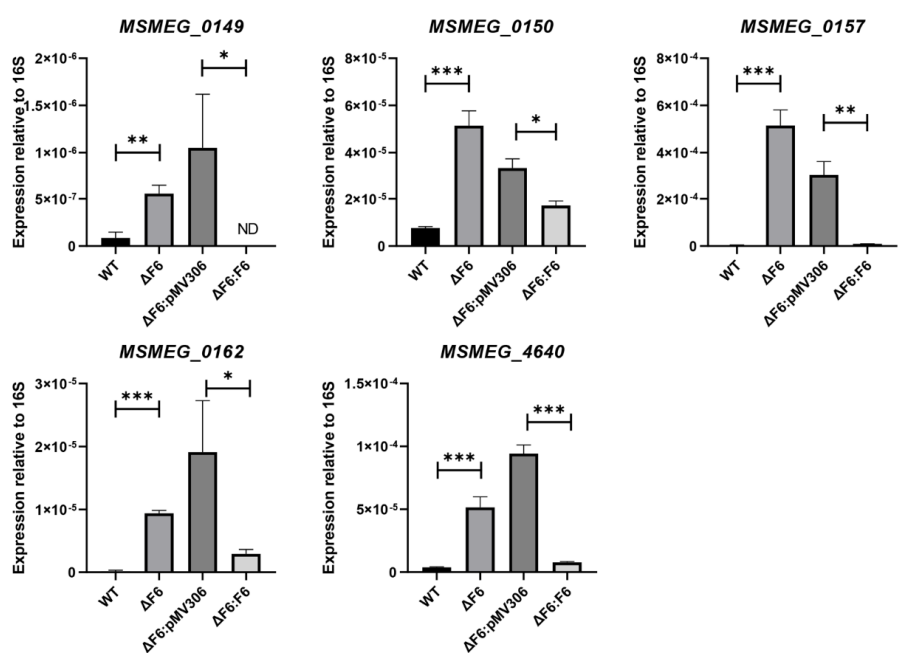

Figure 2. RNA-seq of the $\mathrm{wt}$ and $\Delta \mathrm{F} 6$ strains. (A) Volcano plot of differentially expressed genes (DEGs) constructed using Enhanced Volcano R package [24]. Fold changes of gene expression were plotted. Significant DEGs were identified by $>$ four-fold change (log2 FC $>2$ ) and $<0.05$ FDR, and are shown in red. (B) Schematic representation of the gene clusters upregulated in the $\Delta \mathrm{F} 6$ strain. (C) Northern blotting analysis of F6 transcription in the wt, $\Delta \mathrm{F} 6$, and F6 complemented ( $\triangle$ F6:F6) strains. (D) Validation of DEGs by qRT-PCR. mRNA expression was determined in the wt, $\Delta \mathrm{F} 6, \Delta \mathrm{F} 6: \mathrm{pMV} 306$, and $\Delta \mathrm{F} 6: \mathrm{F6}$ cultures in the mid-log phase and normalized to that of $16 \mathrm{~S}$ rRNA. ${ }^{*} p<0.05,{ }^{* *} p<0.01$, and ${ }^{* * *} p<0.001$. The data are presented as the mean and SD of three biological replicates for each strain. 
To confirm the RNA-seq results, we performed quantitative (q)RT-PCR of several DEGs on RNA templates isolated from the $w \mathrm{t}, \Delta \mathrm{F} 6$, and complemented $(\Delta \mathrm{F} 6$ :F6) strains in the mid-log phase. The complemented strain was constructed by transforming the $\Delta \mathrm{F} 6$ strain with the integrative expression plasmid F6_pMV306, where F6 transcription was driven by the rrnB promoter of $M$. smegmatis. The absence of F6 transcription was confirmed by Northern blotting (Figure $2 \mathrm{C}$ ), which detected no F6 signal in the $\triangle \mathrm{F} 6$ strain. The results demonstrated that MSMEG_0149, MSMEG_0150,MSMEG_0157, MSMEG_0162, and MSMEG_4640 were significantly upregulated after F6 deletion in the $\triangle \mathrm{F} 6$ strain (Figure 2D).

\subsection{F6 Directly Targets 5'-UTR of MSMEG_4640 mRNA}

To identify mRNA targeted by F6, we selected potential targets using the CopraRNA prognostic software (http:/ / rna.informatik.uni-freiburg.de, accessed on 20 May 2019), and compared the list of targets with that of DEGs according to RNA-seq. The only gene present in both lists was MSMEG_4640. F6 deletion caused the upregulation of MSMEG_4640 at both the mRNA and protein levels, which was confirmed by qRT-PCR (Figure 2D) and Western blotting (Figure $3 \mathrm{~A}$ ) of wt and $\Delta \mathrm{F} 6$ cells.

A

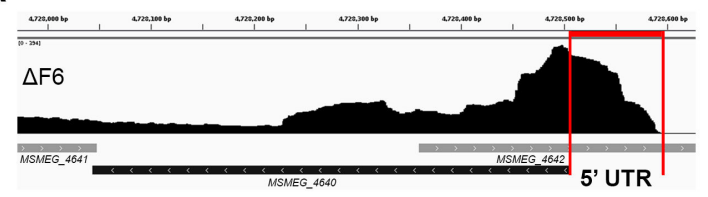

C

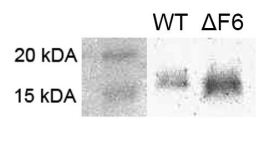

B

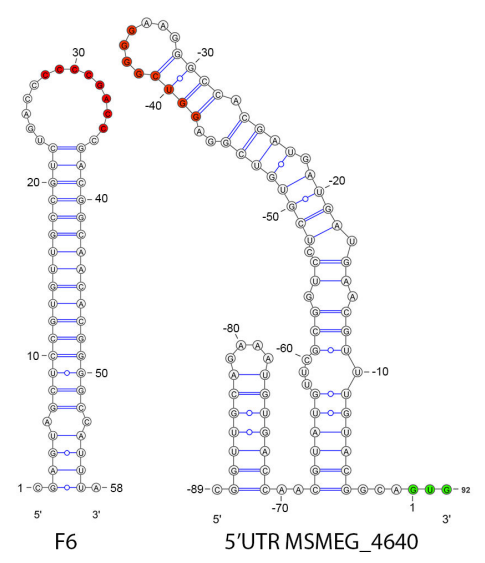

D

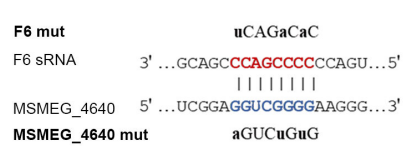

$E$

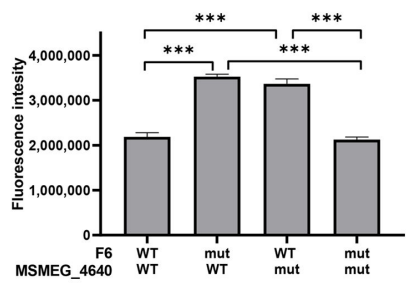

Figure 3. F6 of $M$. smegmatis directly interacts with the $5^{\prime}$-UTR of $M S M E G \_4640$. (A) Inhibition of RpfE2 protein expression by F6. The wt and $\triangle \mathrm{F} 6$ cultures were analyzed for RpfE2 expression by Western blotting using antibodies against the Rpf conserved domain. The RpfE2 molecular mass is $15.1 \mathrm{kDa}$ according to Mycobrowser data (https:/ / mycobrowser.epfl.ch/genes/MSMEG_4640, accessed on 28 June 2021). (B) The coverage track of the MSMEG_4640 locus in Integrative Genomics Viewer [25]. RNA-seq data of the $\Delta \mathrm{F} 6$ strain in the mid-log growth phase are shown. The $5^{\prime}$-UTR is marked by vertical red lines. (C) Secondary structures of F6 and the $5^{\prime}$-UTR of MSMEG_4640. The interacted nucleotides are shown as red dots; green dots mark the start codon. (D) Schematic representation of the interaction between F6 and its target MSMEG_4640. The F6 seed region is in red and the complementary $5^{\prime}$-UTR region is in blue. The introduced mutations are shown above and below. (E) The reporter assay illustrating the direct regulation of MSMEG_4640 by F6. The $5^{\prime}$-UTR of MSMEG_4640 was fused to the GFP gene and reciprocal mutations were introduced in the putative interaction sites on F6 and MSMEG_4640-GFP. GFP translation was estimated by fluorescence. The data are presented as the mean $\pm \mathrm{SD}$ of three biological replicates for each strain; ${ }^{* * *} p<0.001$. 
The RNA-seq profiles revealed that MSMEG_4640 mRNA contained a 90 nt-long 5' UTR (Figure 3B), which had a secondary structure with a loop from -30 to $-38 \mathrm{nt}$ upstream of the start codon; this 8-nt loop was complementary to the F6 loop, thus enabling the formation of an intermolecular duplex (Figure 3C).

To examine whether F6 directly interacted with the 5'-UTR of MSMEG_4640 mRNA, we performed an expression reporter assay with the GFP gene, which was fused to the $5^{\prime}$-UTR fragment. The integrative plasmid carrying this reporter was transfected into the wt and $\Delta \mathrm{F} 6$ strains. Then, we introduced point mutations in the F6 seed region and the putative binding site in the $5^{\prime}$-UTR, and evaluated their effects on GFP expression by measuring fluorescence. In cases of complete complementarity ('wt vs. $\mathrm{wt}^{\prime}$ ' and 'mut vs. mut'; Figure 3D,E), GFP expression was lower than in partly complementary duplexes ('wt vs. mut' and 'mut vs. $\mathrm{wt}^{\prime}$ '), indicating that mutations destroyed the duplex and abrogated the regulation of target gene expression. These results demonstrated that F6 regulated MSMEG_4640 expression through direct interaction between the 8-nt F6 seed sequence and the perfectly complementary region in the 5'-UTR of the MSMEG_4640 mRNA.

\subsection{F6 Expression Abrogates M. smegmatis Entry into Dormancy}

According to a previous study [4], F6 expression in M. tuberculosis increases approximately two-fold by acid and oxidative stresses. To compare F6 expression in M. tuberculosis and M. smegmatis, we evaluated $\mathrm{F} 6$ expression in the wt strain under low $\mathrm{pH}$ and oxidative stress by Northern blotting. The results revealed that F6 expression was only slightly reduced by low $\mathrm{pH}$ and was not changed after $\mathrm{H}_{2} \mathrm{O}_{2}$ treatment (Figure $4 \mathrm{~A}$ ).

A

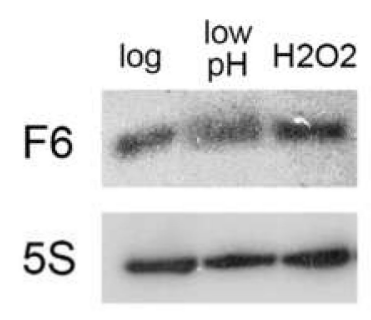

B

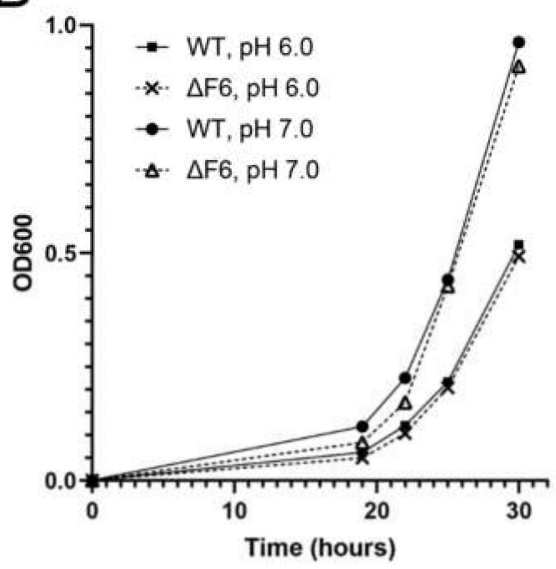

C

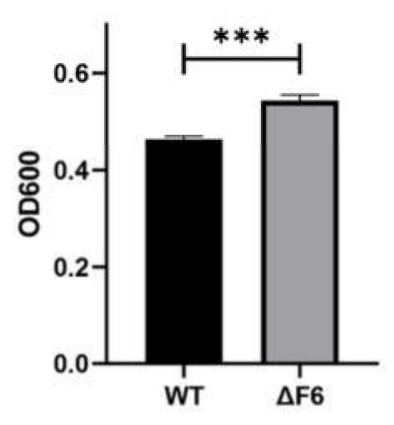

Figure 4. Effects of oxidative and acidic stresses on the M. smegmatis $\Delta \mathrm{F} 6$ and wt strains. (A) F6 transcription in the mid-log growth phase and under acidic (low pH) and oxidative $\left(\mathrm{H}_{2} \mathrm{O}_{2}\right)$ stresses was analyzed by Northern blotting. (B) Growth at neutral ( $\mathrm{pH}$ 7) and acidic ( $\mathrm{pH}$ 6) conditions. (C) Growth under oxidative stress $\left(0.5 \mathrm{mM} \mathrm{H}_{2} \mathrm{O}_{2}\right)$ at eight hours after $\mathrm{H}_{2} \mathrm{O}_{2}$ addition. The data are presented as the mean \pm SD of three independent experiments; ${ }^{* * *} p<0.001$.

Then, we compared the growth of the wt and $\Delta \mathrm{F} 6$ strains under oxidative and acid stresses. There were no significant differences between the wt and $\Delta \mathrm{F} 6$ strains after acid stress (Figure $4 \mathrm{~B}$ ); however, the $\Delta \mathrm{F} 6$ strain showed faster growth than the wt strain after $\mathrm{H}_{2} \mathrm{O}_{2}$ treatment (Figure $4 \mathrm{C}$ ), which could be attributed to the induction of the OxyR regulon controlling the oxidative stress response in mycobacteria [22].

Thus, our results demonstrated that F6 directly targeted the 5'-UTR of MSMEG_4640 and regulated its expression. To check whether $\mathrm{F} 6$ affects expression and biological function of RpfE2, we tested the ability of the $\Delta \mathrm{F} 6 \mathrm{M}$. smegmatis strain to transit to the dormant non-culturable state [18] and to resuscitate from dormancy. Because $r p f$ genes in mycobacteria are involved in these processes [16,26], possible phenotypic changes might be noticed in the specific dormancy-resuscitation system rather than during active bacterial growth 
in vitro. Rpf-mediated resuscitation of dormant 'non-culturable' bacteria of both the wt and $\Delta \mathrm{F} 6$ strains was performed by co-cultivation with exponentially growing Micrococcus Luteus, which secretes Rpfs, according to the procedure described earlier [18]. The strains demonstrated similar abilities to transit from the non-culturable to the culturable state (Figure 5A,B). However, a phenotypic difference between the strains was found in the process of entering dormancy as the $\triangle \mathrm{F} 6$ strain demonstrated significantly higher culturability under stress than the wt strain (Figure 5C,D); furthermore, analysis of MSMEG_4640 expression revealed transcripts only in the $\Delta \mathrm{F} 6$ strain (Figure $5 \mathrm{E}$ ).

A

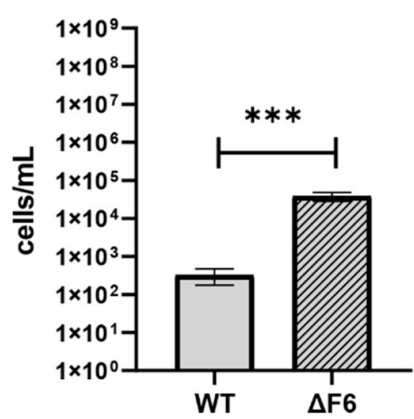

D

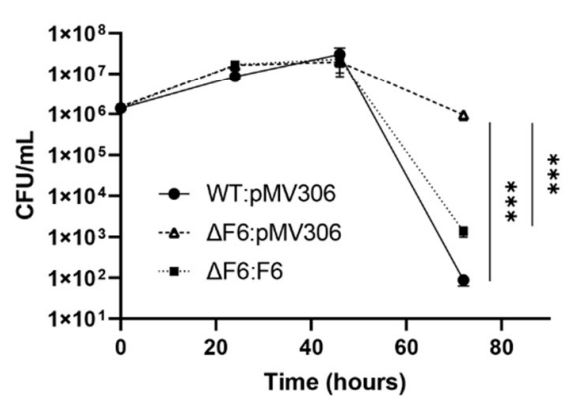

B

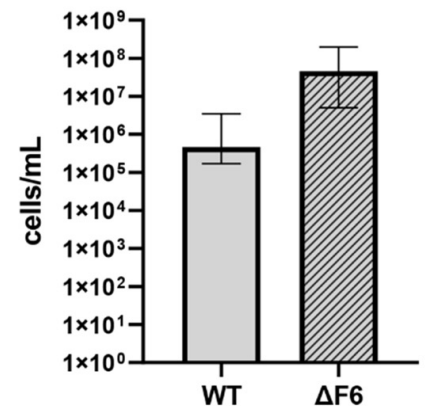

E

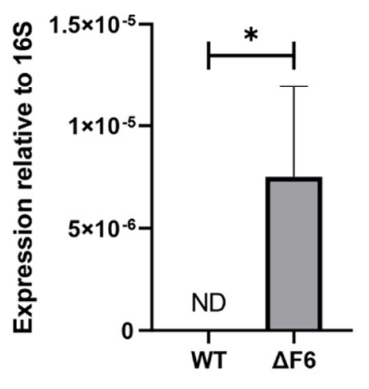

WT

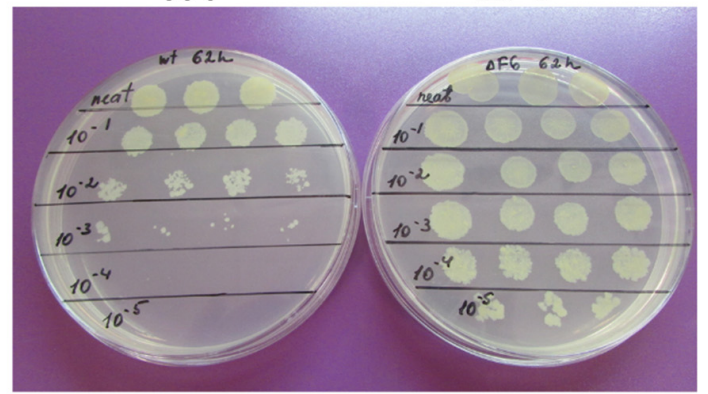

$\Delta \mathrm{F6}: \mathrm{pMV306}$

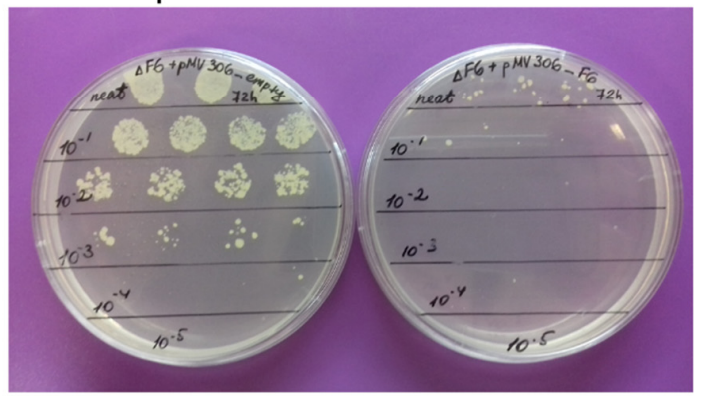

Figure 5. F6 regulates the transition of M. smegmatis to dormancy under growth-limiting conditions. (A) Colony-forming unit (CFU) concentration for M. smegmatis wt and $\Delta \mathrm{F} 6$ strains growing in potassium-limiting conditions at the point of minimal culturability $(65 \mathrm{~h}$ ). (B) Reactivation of dormant 'non-culturable' M. smegmatis cells in the wt and $\Delta \mathrm{F} 6$ strains co-cultured with M. luteus at the point of minimal culturability $(65 \mathrm{~h})$ in standard Sauton's medium (most probable numbers, MPN). (C) Culturability of $M$. smegmatis wt and $\triangle \mathrm{F} 6$ strains under potassium-limiting conditions. (D) Growth of $M$. smegmatis wt, $\triangle \mathrm{F} 6: \mathrm{pMV} 306$, and $\Delta \mathrm{F} 6: \mathrm{F} 6$ strains in potassium-deficient medium. (E) qRT-PCR analysis of MSMEG_4640 expression in wt and $\triangle \mathrm{F} 6$ cultures growing under potassium limiting conditions $(45 \mathrm{~h})$. The data are presented as the mean $\pm \mathrm{SD}$ of four $(\mathbf{A}, \mathbf{B}, \mathbf{D})$ or three (E) biological replicates for each strain; ${ }^{*} p<0.05$ and ${ }^{* * *} p<0.001$.

F6 complementation was found to partially restore the ability of the mutant to form dormant 'non-culturable' cells under potassium-limiting conditions (Figure 5C,D), indicating the involvement of RpfE2 and F6 sRNA in maintaining M. smegmatis culturability in stressful conditions and in ability to transit to dormancy.

\section{Discussion}

Despite differences in many aspects such as lifestyle and growth rate, M. smegmatis and $M$. tuberculosis share a sufficient number of highly homologous sRNAs. A combined computational and experimental approach has identified sRNAs from M. tuberculosis and $M$. smegmatis and revealed that the expression of many sRNAs is conserved across the mycobacterial species [10].

In this study, we investigated F6, an M. smegmatis sRNA which is highly conserved among mycobacterial species, including $M$. tuberculosis, where F6 has been characterized $[4,13]$. The Arnvig's group has demonstrated that in M. tuberculosis, F6 is upregulated during star- 
vation through the activity of transcription factor SigF, and in turn activates the synthesis of chaperonins GroES and GroEL2, promoting M. tuberculosis survival in granulomas [13].

Comparison of the F6 promoter regions in $M$. tuberculosis and M. smegmatis shows that the SigF binding site $(-35 \mathrm{nt})$ characteristic for $M$. tuberculosis disappears in the M. smegmatis genome, where it is changed for the SigD consensus GTAACG [27]. In mycobacteria, SigD expression is upregulated under starvation and decreases during hypoxia [28]. The F6 regulation in mycobacteria should be further investigated, but in M. smegmatis this sRNA is not controlled by SigF.

In search for potential mRNA targets of F6 in M. smegmatis, we constructed an unmarked F6 deletion strain and used RNA-seq to determine DEGs in the F6 knockout strain compared to the wt strain. Among the $15 \mathrm{DEGs}$, which were all upregulated in the $\Delta \mathrm{F} 6$ mutant, the overwhelming majority (MSMEG_0157-MSMEG_0162) are under control of the oxidative stress response regulator OxyS (MSMEG_0156) [22]. The $\triangle \mathrm{F} 6$ strain grew faster than the wt strain under oxidative stress (Figure $4 \mathrm{~B}$ ), which was possibly due to the upregulation of these genes. However, we have not yet determined any direct connection between this phenomenon and F6 deletion.

By using the combination of RNA-seq data and bioinformatic predictions, we found that F6 targeted the 5'-UTR of MSMEG_4640 mRNA and that the direct interaction between the F6 seed with the target led to the downregulation of MSMEG_4640-encoded protein RpfE2. The search for the phenotype associated with the activity of F6 sRNA revealed that under non-optimal conditions induced by potassium deficiency, the mutant strain continued to grow, whereas the wt strain entered dormancy and the non-culturable state.

RpfE2 encoded by MSMEG_4640 is a secreted protein belonging to the family of resuscitation-promoting factors (Rpfs) that act as growth stimulators through their lysozymelike activity towards peptidoglycan in the bacterial cell wall [29]. The secreted Rpf initially found in Micrococcus luteus has been shown to initiate the reactivation of dormant cells and stimulate the replication of growing cells [30,31], including G+C-rich bacilli, particularly of the genus Mycobacterium [30]. Rpf-like secreted proteins characterized by the presence of a conservative domain of 75 amino acids have been found in some other Actinobacteria species. M. smegmatis has four and M. tuberculosis--five rpf genes.

Recombinant Rpfs have been shown to effectively stimulate the reactivation of dormant 'non-culturable' M. tuberculosis [32,33] and M. smegmatis [18] cells. In contrast to Micrococcus luteus, $\mathrm{KO}$ mutants for $r p f$ genes in $M$. tuberculosis are viable both in vitro and in vivo. A mutation in one of the five genes encoding Rpfs in M. tuberculosis do not stop cell growth or affect the reactivation process, indicating certain redundancy in the activity of Rpfs and their mutual compensatory effects; however, such mutations can cause changes in cell morphology [16,34].

To find the functional meaning of the F6-rpfE2 interaction, we used the M. smegmatis dormancy model when mycobacteria are grown in nutrient-inappropriate potassiumdeficient medium resulting in a stable non-culturable state [18]. It was demonstrated that resuscitation of these dormant $M$. smegmatis has Rpf-mediated nature [18].

Rpf proteins in $M$. smegmatis have not been thoroughly studied yet. The relationship between biofilm formation and Rpfs in $M$. smegmatis has been recently demonstrated by Ealand et al. [35]; they observed that simultaneous deletion of $r p f$ genes hampered the development of biofilms and reduced drug tolerance, and that these effects were accompanied by a decrease in muropeptide production and altered peptidoglycan cross-linking. Recently, the same group has examined the role of $M$. tuberculosis Rpfs in reactivation processes by expressing them in M. smegmatis [36]. Their results indicate that the growth stimulatory effect observed with the culture filtrate is most likely the result of a combination of Rpfs with other factors [36]. In our study, the changes in RpfE2 expression had a dramatic effect on M. smegmatis entering into the 'non-culturable' state but did not affect its reactivation from dormancy.

Despite many attempts to clarify the processes of mycobacteria entry into and reactivation from the dormant state, they are still poorly understood. Our results indicate 
that the ability of M. smegmatis to switch to the dormant 'non-culturable' state in order to survive in stressful surroundings is regulated by F6 sRNA, which directly interacts with MSMEG_4640 mRNA, inhibiting the expression of the encoded resuscitation factor RpfE2. Thus, M. smegmatis F6 sRNA may contribute to bacterial tolerance to and persistence in stressful environmental conditions.

\section{Materials and Methods}

\subsection{Bacterial Strains, Media, and Growth Conditions}

M. smegmatis mc $^{2} 155$ cells from the bacterial collection of the Bach Institute of Biochemistry (Research Center of Biotechnology of the Russian Academy of Sciences, Moscow, Russia) and mutant M. smegmatis strains were pre-cultured from frozen stock in Nutrient Broth rich medium (Himedia, India) supplemented with 0.05\% (v/v) Tween 80 for $30 \mathrm{~h}$ at $37^{\circ} \mathrm{C}$ on an orbital shaker (200 rpm), and then regrown in Sauton's medium [37] supplemented with $0.05 \%$ Tween 80 .

For stress survival experiments, $M$. smegmatis $\mathrm{mc}^{2} 155$ were grown to the early logarithmic phase $\left(\mathrm{OD}_{600}=0.3\right)$ in Sauton's medium supplemented with $0.05 \%$ Tween 80 . To simulate acidic or oxidative stresses, cultures were incubated at $37^{\circ} \mathrm{C}$ on an orbital shaker $(200 \mathrm{rpm})$ with $\mathrm{HCl}(5 \mu \mathrm{M})$ for $2 \mathrm{~h}$ or with $\mathrm{H}_{2} \mathrm{O}_{2}(5 \mu \mathrm{M})$ for $8 \mathrm{~h}$, respectively. Control cultures were grown in parallel with the stressed cultures.

For cloning procedures, Escherichia coli DH5 $\alpha$ was grown in Luria Bertani (LB) broth and LB-agar.

Oligonucleotides, plasmids and strains used are listed in Supplementary Table S2.

\subsection{Construction of F6 Deletion $(\Delta F 6)$ and Complementation ( $\triangle F 6:: F 6)$ Strains}

The allelic replacement technique was used to generate an $M$. smegmatis knockout mutant as described previously [20]. Briefly, the right (1476 bp) and left (1440 bp) regions flanking the deletion site were amplified from genomic DNA using primers RHA_F6_for/RHA_F6_rev and LHA-F6_for/LHA-F6_rev and the obtained PCR products were inserted into the p2NIL delivery plasmid at BamHI and HindIII restriction sites, respectively. The $s a c B$ and lacZ selection genes from the pGOAL19 vector were inserted into p2NIL at the PacI restriction site to yield the pF6_new_Knockout suicide plasmid (Supplementary Figure S1), which was used to transform electrocompetent M. smegmatis $\mathrm{mc}^{2} 155$ cells by standard methodology. During the first homologous recombination, clones were selected on a medium containing kanamycin $(20 \mu \mathrm{g} / \mathrm{mL})$, hygromycin $(50 \mu \mathrm{g} / \mathrm{mL})$, and 5-bromo-4-chloro-3-indolyl- $\beta$-D-galactopyranoside (X-gal, $0.4 \%$ ). To obtain a double crossover, the resulting colonies were scattered into cups containing sucrose $(2 \% w / v)$ and $X$-gal, and white colonies were screened for resistance to hygromycin and kanamycin.

Selected colonies were checked for deletion by PCR with primers F6-KO-check_for and F6-KO-check_rev, and the obtained amplicons were sequenced by the Sanger procedure (Evrogen, Moscow, Russia).

To complement the $\Delta \mathrm{F} 6$ strain, electrocompetent cells were transformed with the pMV306_F6 integrating plasmid containing the F6 gene under the rrnB mycobacterial promoter.

\subsection{RNA Isolation}

Bacterial cultures were grown up to the logarithmic phase $\left(\mathrm{OD}_{600}=1.0\right)$ and centrifuged $\left(4^{\circ} \mathrm{C}, 4000 \mathrm{rpm}, 15 \mathrm{~min}\right)$. The pellets were washed twice with fresh medium, rapidly cooled on ice, and centrifuged again. Total RNA was isolated by phenol-chloroform extraction and cell disruption using Bead Beater (BioSpec Products, Bartlesville, OK, USA) as described previously [38] and treated with Turbo DNase (Life Technologies, Carlsbad, CA, USA) to remove traces of genomic DNA. RNA quantity and purity were determined spectrophotometrically and its integrity was assessed by electrophoresis in 1\% agarose gels. 


\section{4. cDNA Synthesis and qRT-PCR}

CDNA was synthesized from $1 \mathrm{mg}$ total RNA using random hexanucleotides and SuperScript III reverse transcriptase (Life Technologies, USA) according to the manufacturer's protocol, and used as a template in qRT-PCR performed with qPCRmix-HS SYBR (Evrogen) in a LightCycler 480 Real-Time PCR system (Roche, Switzerland) at the following cycling conditions: $95{ }^{\circ} \mathrm{C}$ for $20 \mathrm{~s}, 61^{\circ} \mathrm{C}$ for $20 \mathrm{~s}$, and $72{ }^{\circ} \mathrm{C}$ for $30 \mathrm{~s}$, repeated 40 times. Three biological and nine technical replicates were used to ensure reproducibility, and the results were analyzed by LinRegPCR v 2014.6. The data were normalized against $16 \mathrm{~S}$ rRNA to correct for sample-to-sample variation and the relative expression ratios were determined as described earlier [39].

\subsection{Northern Blotting}

To detect F6, $2 \mu \mathrm{g}$ of total RNA isolated from exponential bacterial cultures was separated on $10 \%$ denaturing polyacrylamide gels in $1 \times$ TBE buffer and transferred to Hybond N Membranes (Amersham, UK). The membranes were hybridized overnight at $42{ }^{\circ} \mathrm{C}$ in ULTRAhyb-Oligo hybridization buffer (Life Technologies) with oligonucleotides F6_NB and 5S_NB, which were $5^{\prime}$-end-radiolabeled (15 pmoles) using $10 \mu \mathrm{Ci}$ of [ $\left.\gamma 32 \mathrm{P}\right]$-ATP and T4 polynucleotide kinase (Fermentas, Lithuania). After hybridization, the membranes were washed three times in $1 \times$ saline-sodium citrate buffer with $0.1 \%$ SDS and exposed to X-ray films Retina (Carestream Health, Rochester, NY, USA) to detect radioactivity.

\subsection{Western Blotting}

Bacterial cells were lysed using Bead Beater (BioSpec Products) and heated for $5 \mathrm{~min}$ at $95^{\circ} \mathrm{C}$ in $2 \times$ sodium dodecyl sulfate (SDS) sample buffer ( $100 \mathrm{mM}$ of Tris- $\mathrm{HCl}, \mathrm{pH} 6.8,4 \%$ SDS, $0.2 \%$ Bromophenol Blue, $20 \%$ glycerol, and $200 \mathrm{mM}$ of DTT). Protein concentration was measured by the Bradford assay. Equal amounts of total protein $(5 \mu \mathrm{g})$ were resolved by SDS-PAGE in a $12 \%$ gel and transferred onto Hybond-P membranes (GE Healthcare, Little Chalfont, UK), which were blocked with 5\% w/v nonfat dry milk (Bio-Rad, Hercules, CA, USA) and incubated with primary antibodies against the conservative Rpf domain [31] and then with secondary anti-rabbit horseradish peroxidase (HRP)-conjugated IgG (Cell Signaling Technology, Beverly, MA, USA). Specific signals were visualized using a Clarity Western ECL (Bio-Rad) in a Bio-Rad ChemiDoc Touch imager station.

\subsection{Libraries for RNA-Seq and Data Analyses}

RNA samples were depleted of rRNA using the Ribo-Zero rRNA Removal Kit (Bacteria) (Epicentre, Madison, WI, USA) and used to generate sequencing libraries with the NEBNext Ultra II Directional RNA Library Prep Kit (NEB, USA) according to the manufacturers' protocol. Sequencing was performed in triplicate using the Illumina HiSeq2500 as the pair-ended $100 \mathrm{nt}$ reads. After quality control evaluation, the reads were mapped on the reference M. smegmatis genome (NC_008596.1, http:/ / www.ncbi.nlm.nih.gov /, accessed on 18 May 2019) by Bowtie2 [40]; the alignment was performed with the "-local" and "-dovetail" options. Calculation of the mapped fragments for all genes was performed using the featureCounts program from the package Subread [41]. Only unambiguously mapped non-chimeric fragments were used in the subsequent analysis.

DEGs were identified by the edgeR software package [42]. The genes were considered to be differentially expressed if the FDR value was $\leq 0.05$ and the expression change module (fold change, FC) was $\geq 4$.

\subsection{RNA-Seq and Visualization of the RNA Secondary Structure}

Visualization of the depth of RNA sequencing coverage was carried out in the IGV genomic browser [25] using the deepTools tool suite [43]. The volcano plot of DEGs was constructed using the EnhancedVolcano R package [24].

Secondary structures of F6 and MSMEG_4640 5'-UTR were determined by the RNAfold web server [44] and visualized using VARNA applet [45]. 


\subsection{GFP Fluorescence Assay}

The following $M$. smegmatis strains were used for analysis:

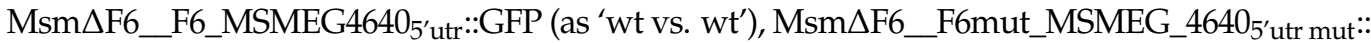
GFP (as 'mut vs. mut'), Msm_ MSMEG4640 ${ }^{\prime}$ 'utrmut ::GFP (as 'wt vs. mut'), and $\mathrm{Msm} \Delta \mathrm{F} 6$ _F6mut_MSMEG4640_'utr::GFP (as 'mut vs. wt'). Strains' descriptions are given in Supplementary Table S2.

To measure fluorescence, the strains were grown to the logarithmic phase $\left(\mathrm{OD}_{600}=0.8\right)$ in LB broth supplemented with $0.05 \%$ Tween 80 and kanamycin $(25 \mu \mathrm{g} / \mathrm{mL})$. Cells were pelleted by centrifugation, washed twice, resuspended in $1 \times$ PBS buffer, and lysed using Bead Beater (BioSpec Products) as described previously [38]. The lysate was centrifuged $\left(4{ }^{\circ} \mathrm{C}, 4000 \mathrm{rpm}, 5 \mathrm{~min}\right)$ and the supernatant transferred to 96 -well plates $(200 \mu \mathrm{L}$ per well). GFP fluorescence was measured on a Tecan ${ }^{\mathrm{TM}}$ GENios ${ }^{\circledR}$ Microplate Reader fluorometer (Tecan, Salzburg, Austria) with excitation and emission wavelengths of 488 and $510 \mathrm{~nm}$, respectively. The results were expressed as the mean $\pm \mathrm{SD}$, calculated based on three biological replicates.

\subsection{Dormant M. smegmatis Cells}

Cultures grown in the Nutrient Broth rich medium (Himedia, India) were inoculated $(1 \mathrm{~mL})$ into $150 \mathrm{~mL}$ of modified $\mathrm{K}+$-free Hartman's-de Bont (mHdeB) medium containing (per liter): $11.8 \mathrm{~g} \mathrm{Na}_{2} \mathrm{HPO}_{4} \cdot 12 \mathrm{H}_{2} \mathrm{O}, 1.7 \mathrm{~g}$ citric acid, $20 \mathrm{~g}\left(\mathrm{NH}_{4}\right)_{2} \mathrm{SO}_{4}, 30 \mathrm{~mL}$ glycerol, $0.05 \%$ Tween 80, and $10 \mathrm{~mL}$ of trace elements solution ( $1 \mathrm{~g}$ EDTA, $10 \mathrm{~g} \mathrm{MgCl}_{2} \cdot 6 \mathrm{H}_{2} \mathrm{O}$, $0.1 \mathrm{~g} \mathrm{CaCl}_{2} \cdot 2 \mathrm{H}_{2} \mathrm{O}, 0.04 \mathrm{~g} \mathrm{CoCl}_{2} \cdot 6 \mathrm{H}_{2} \mathrm{O}, 0.1 \mathrm{~g} \mathrm{MnCl}_{2} \cdot 2 \mathrm{H}_{2} \mathrm{O}, 0.02 \mathrm{~g} \mathrm{Na}_{2} \mathrm{MoO}_{4} \cdot 2 \mathrm{H}_{2} \mathrm{O}, 0.2 \mathrm{~g}$ $\mathrm{ZnSO}_{4} \cdot 7 \mathrm{H}_{2} \mathrm{O}, 0.02 \mathrm{~g} \mathrm{CuSO}_{4} \cdot 5 \mathrm{H}_{2} \mathrm{O}$, and $0.5 \mathrm{~g} \mathrm{FeSO}_{4} \cdot 7 \mathrm{H}_{2} \mathrm{O}$ per liter). The components were mixed, the medium $\mathrm{pH}$ adjusted to 7.0 , and $0.05 \%(v / v)$ Tween 80 and $0.5 \%$ BSA (Cohn-Analog, Sigma, St Louis, MO, USA) were added; for plasmid-containing strains, growth media were supplemented with kanamycin $(50 \mu \mathrm{g} / \mathrm{mL})$. Cultures were incubated at $37^{\circ} \mathrm{C}$ on an orbital shaker (200 rpm.)

\subsection{Viability Assay}

Bacterial suspensions were serially diluted in fresh medium, and $100 \mu \mathrm{L}$ from each dilution was spread on agar-solidified NBE and incubated at $37^{\circ} \mathrm{C}$. The number of colonyforming units (CFUs) was determined after 5 days.

\subsection{Resuscitation Assay}

Resuscitation and calculation of most probable numbers (MPNs) of viable M. smegmatis cells were performed in 48-well plastic plates (Corning) containing $450 \mu \mathrm{L}$ Sauton's medium supplemented with $10^{5}-10^{6} \mathrm{M}$. luteus cells from exponentially growing cultures. M. luteus cells did not interfere with the calculation of $M$. smegmatis growth as they do not multiply in Sauton's medium. Ten-fold serially diluted samples of $M$. smegmatis cultures (50 $\mu \mathrm{L}$ ) were added to each well and plates were incubated at $37^{\circ} \mathrm{C}$ with agitation at $100 \mathrm{rpm}$ for 7 days. Wells with visible bacterial growth were counted as positive and MPN values were calculated using standard statistical methods.

\subsection{Statistical Analysis}

Statistical analysis was performed using Microsoft office Excel 2007 and GraphPad Prism 6.0 (GraphPad Software Inc., La Jolla, CA, USA). The data were expressed as the mean \pm SD. For non-normally distributed data, the Mann-Whitney $U$ test was used. Differences were considered statistically significant at $p<0.05$. At least three independent experiments were performed for each assay.

Supplementary Materials: The following data are available online at https://www.mdpi.com/ article/10.3390/ijms222111536/s1.

Author Contributions: Conceptualization, E.G.S. and T.A.; methodology, A.K. and T.A.; software, A.G.; validation, O.B., Y.S. and E.G.S.; formal analysis, T.A.; investigation, O.B., A.M., Y.S., T.S. and 
E.G.S.; resources, T.A.; data curation, A.K. and T.A.; writing-original draft preparation, A.G., O.B., E.G.S. and T.A.; writing-review and editing, E.G.S. and T.A.; visualization, A.G.; supervision, A.K. and T.A.; project administration, T.A.; funding acquisition, T.A. All authors have read and agreed to the published version of the manuscript.

Funding: This research was funded by RFBR grant No. 16-04-01247. E.G.S. and A.K are grateful to the State Contract from the Russian Federation for financial support.

Institutional Review Board Statement: Not applicable.

Informed Consent Statement: Not applicable.

Data Availability Statement: All RNA-seq data generated for this study has been deposited in the GEO repository under accession number GSE149173 (https:/ / www.ncbi.nlm.nih.gov/geo/query/ acc.cgi?acc $=$ GSE149173, accessed on 31 May 2021.)

Acknowledgments: The authors are grateful to Dmitry Ignatov (Max Plank Unit for the Science of Pathogens, Germany) who initiated this work.

Conflicts of Interest: The authors declare no conflict of interest.

\section{References}

1. Holmqvist, E.; Wagner, E.G.H. Impact of bacterial sRNAs in stress responses. Biochem. Soc. Trans. 2017, 45, 1203-1212. [CrossRef]

2. Papenfort, K.; Vogel, J. Regulatory RNA in bacterial pathogens. Cell Host Microbe 2010, 8, 116-127. [CrossRef]

3. Waters, L.S.; Storz, G. Regulatory RNAs in bacteria. Cell 2009, 136, 615-628. [CrossRef]

4. Arnvig, K.B.; Young, D.B. Identification of small RNAs in Mycobacterium tuberculosis. Mol. Microbiol. 2009, 73, 397-408. [CrossRef]

5. Gerrick, E.R.; Barbier, T.; Chase, M.R.; Xu, R.; François, J.; Lin, V.H.; Szucs, M.J.; Rock, J.M.; Ahmad, R.; Tjaden, B. Small RNA profiling in Mycobacterium tuberculosis identifies MrsI as necessary for an anticipatory iron sparing response. Proc. Natl. Acad. Sci. USA 2018, 115, 6464-6469. [CrossRef] [PubMed]

6. Haning, K.; Cho, S.H.; Contreras, L.M. Small RNAs in mycobacteria: An unfolding story. Front. Cell. Infect. Microbiol. 2014, 4, 96. [CrossRef]

7. Ostrik, A.A.; Azhikina, T.L.; Salina, E.G. Small Noncoding RNAs and Their Role in the Pathogenesis of Mycobacterium tuberculosis Infection. Biochemistry 2021, 86, S109-S119. [PubMed]

8. Schwenk, S.; Arnvig, K.B. Regulatory RNA in Mycobacterium tuberculosis, back to basics. Pathog. Dis. 2018, 76, fty035. [CrossRef] [PubMed]

9. Taneja, S.; Dutta, T. On a stake-out: Mycobacterial small RNA identification and regulation. Non-Coding RNA Res. 2019, 4, 86-95. [CrossRef]

10. DiChiara, J.M.; Contreras-Martinez, L.M.; Livny, J.; Smith, D.; McDonough, K.A.; Belfort, M. Multiple small RNAs identified in Mycobacterium bovis BCG are also expressed in Mycobacterium tuberculosis and Mycobacterium smegmatis. Nucleic Acids Res. 2010, 38, 4067-4078. [CrossRef]

11. Ignatov, D.; Malakho, S.; Majorov, K.; Skvortsov, T.; Apt, A.; Azhikina, T. RNA-Seq analysis of Mycobacterium avium non-coding transcriptome. PLOS ONE 2013, 8, e74209.

12. Tsai, C.-H.; Baranowski, C.; Livny, J.; McDonough, K.A.; Wade, J.T.; Contreras, L.M. Identification of novel sRNAs in mycobacterial species. PLoS ONE 2013, 8, e79411. [CrossRef] [PubMed]

13. Houghton, J.; Rodgers, A.; Rose, G.; D’Halluin, A.; Kipkorir, T.; Barker, D.; Waddell, S.J.; Arnvig, K.B. The Mycobacterium tuberculosis sRNA F6 modifies expression of essential chaperonins, GroEL2 and GroES. bioRxiv 2021. [CrossRef]

14. Shiloh, M.U.; Champion, P.A.D. To catch a killer. What can mycobacterial models teach us about Mycobacterium tuberculosis pathogenesis? Curr. Opin. Microbiol. 2010, 13, 86-92. [CrossRef] [PubMed]

15. Maione, V.; Ruggiero, A.; Russo, L.; De Simone, A.; Pedone, P.V.; Malgieri, G.; Berisio, R.; Isernia, C. NMR structure and dynamics of the resuscitation promoting factor RpfC catalytic domain. PLoS ONE 2015, 10, e0142807. [CrossRef] [PubMed]

16. Kana, B.D.; Gordhan, B.G.; Downing, K.J.; Sung, N.; Vostroktunova, G.; Machowski, E.E.; Tsenova, L.; Young, M.; Kaprelyants, A.; Kaplan, G. The resuscitation-promoting factors of Mycobacterium tuberculosis are required for virulence and resuscitation from dormancy but are collectively dispensable for growth in vitro. Mol. Microbiol. 2008, 67, 672-684. [CrossRef]

17. Shleeva, M.; Goncharenko, A.; Kudykina, Y.; Young, D.; Young, M.; Kaprelyants, A. Cyclic AMP-dependent resuscitation of dormant Mycobacteria by exogenous free fatty acids. PLoS ONE 2013, 8, e82914. [CrossRef] [PubMed]

18. Shleeva, M.; Mukamolova, G.V.; Young, M.; Williams, H.D.; Kaprelyants, A.S. Formation of 'non-culturable'cells of Mycobacterium smegmatis in stationary phase in response to growth under suboptimal conditions and their Rpf-mediated resuscitation. Microbiology 2004, 150, 1687-1697. [CrossRef]

19. Parish, T.; Stoker, N.G. Use of a flexible cassette method to generate a double unmarked Mycobacterium tuberculosis tlyA plcABC mutant by gene replacement. Microbiology 2000, 146, 1969-1975. [CrossRef] 
20. Kendall, S.L.; Frita, R. Construction of targeted mycobacterial mutants by homologous recombination. In Mycobacteria Protocols; Springer: Berlin/Heidelberg, Germany, 2009; pp. 297-310.

21. Sassetti, C.M.; Boyd, D.H.; Rubin, E.J. Genes required for mycobacterial growth defined by high density mutagenesis. Mol. Microbiol. 2003, 48, 77-84. [CrossRef]

22. Daugherty, A.; Powers, K.M.; Standley, M.S.; Kim, C.S.; Purdy, G.E. Mycobacterium smegmatis RoxY is a repressor of oxyS and contributes to resistance to oxidative stress and bactericidal ubiquitin-derived peptides. J. Bacteriol. 2011, 193, $6824-6833$. [CrossRef]

23. Van Rijsewijk, B.R.H.; Kochanowski, K.; Heinemann, M.; Sauer, U. Distinct transcriptional regulation of the two Escherichia coli transhydrogenases PntAB and UdhA. Microbiology 2016, 162, 1672-1679. [CrossRef]

24. Blighe, K.; Rana, S.; Lewis, M. EnhancedVolcano: Publication-Ready Volcano Plots with Enhanced Colouring and Labeling. 2020, R package version 1.8.0; R Package Vignette: Madison, WI, USA, 2021.

25. Robinson, J.T.; Thorvaldsdóttir, H.; Winckler, W.; Guttman, M.; Lander, E.S.; Getz, G.; Mesirov, J.P. Integrative genomics viewer. Nat. Biotechnol. 2011, 29, 24-26. [CrossRef]

26. Downing, K.J.; Mischenko, V.V.; Shleeva, M.O.; Young, D.I.; Young, M.; Kaprelyants, A.S.; Apt, A.S.; Mizrahi, V. Mutants of Mycobacterium tuberculosis lacking three of the five rpf-like genes are defective for growth in vivo and for resuscitation in vitro. Infect. Immun. 2005, 73, 3038-3043. [CrossRef]

27. Raman, S.; Hazra, R.; Dascher, C.C.; Husson, R.N. Transcription regulation by the Mycobacterium tuberculosis alternative sigma factor SigD and its role in virulence. J. Bacteriol. 2004, 186, 6605-6616. [CrossRef]

28. Betts, J.C.; Lukey, P.T.; Robb, L.C.; McAdam, R.A.; Duncan, K. Evaluation of a nutrient starvation model of Mycobacterium tuberculosis persistence by gene and protein expression profiling. Mol. Microbiol. 2002, 43, 717-731. [CrossRef] [PubMed]

29. Telkov, M.; Demina, G.; Voloshin, S.; Salina, E.G.; Dudik, T.; Stekhanova, T.; Mukamolova, G.V.; Kazaryan, K.; Goncharenko, A.; Young, M. Proteins of the Rpf (resuscitation promoting factor) family are peptidoglycan hydrolases. Biochemistry 2006, 71, 414-422. [CrossRef] [PubMed]

30. Mukamolova, G.V.; Kaprelyants, A.S.; Young, D.I.; Young, M.; Kell, D.B. A bacterial cytokine. Proc. Natl. Acad. Sci. USA 1998, 95, 8916-8921. [CrossRef] [PubMed]

31. Mukamolova, G.V.; Turapov, O.A.; Kazarian, K.; Telkov, M.; Kaprelyants, A.S.; Kell, D.B.; Young, M. The rpf gene of Micrococcus luteus encodes an essential secreted growth factor. Mol. Microbiol. 2002, 46, 611-621. [CrossRef] [PubMed]

32. Biketov, S.; Mukamolova, G.V.; Potapov, V.; Gilenkov, E.; Vostroknutova, G.; Kell, D.B.; Young, M.; Kaprelyants, A.S. Culturability of Mycobacterium tuberculosis cells isolated from murine macrophages: A bacterial growth factor promotes recovery. FEMS Immunol. Med. Microbiol. 2000, 29, 233-240. [CrossRef] [PubMed]

33. Shleeva, M.; Bagramyan, K.; Telkov, M.; Mukamolova, G.; Young, M.; Kell, D.; Kaprelyants, A. Formation and resuscitation of 'non-culturable' cells of Rhodococcus rhodochrous and Mycobacterium tuberculosis in prolonged stationary phase. Microbiology 2002, 148, 1581-1591. [CrossRef] [PubMed]

34. Hartmann, M.; Barsch, A.; Niehaus, K.; Pühler, A.; Tauch, A.; Kalinowski, J. The glycosylated cell surface protein Rpf2, containing a resuscitation-promoting factor motif, is involved in intercellular communication of Corynebacterium glutamicum. Arch. Microbiol. 2004, 182, 299-312. [CrossRef] [PubMed]

35. Ealand, C.; Rimal, B.; Chang, J.; Mashigo, L.; Chengalroyen, M.; Mapela, L.; Beukes, G.; Machowski, E.; Kim, S.J.; Kana, B. Resuscitation-promoting factors are required for Mycobacterium smegmatis biofilm formation. Appl. Environ. Microbiol. 2018, 84, e00687-18. [CrossRef] [PubMed]

36. Gordhan, B.G.; Peters, J.S.; McIvor, A.; Machowski, E.E.; Ealand, C.; Waja, Z.; Martinson, N.; Kana, B.D. Detection of differentially culturable tubercle bacteria in sputum using mycobacterial culture filtrates. Sci. Rep. 2021, 11, 1-11. [CrossRef] [PubMed]

37. Connell, N.D. Mycobacterium: Isolation, maintenance, transformation, and mutant selection. Methods Cell Biol. 1995, 45, 107-125.

38. Rustad, T.R.; Roberts, D.M.; Liao, R.P.; Sherman, D.R. Isolation of mycobacterial RNA. In Mycobacteria Protocols; Springer: Berlin/Heidelberg, Germany, 2009; pp. 13-22.

39. Ganger, M.T.; Dietz, G.D.; Ewing, S.J. A common base method for analysis of qPCR data and the application of simple blocking in qPCR experiments. BMC Bioinform. 2017, 18, 1-11. [CrossRef] [PubMed]

40. Langmead, B.; Salzberg, S.L. Fast gapped-read alignment with Bowtie 2. Nat. Methods 2012, 9, 357-359. [CrossRef] [PubMed]

41. Liao, Y.; Smyth, G.K.; Shi, W. featureCounts: An efficient general purpose program for assigning sequence reads to genomic features. Bioinformatics 2014, 30, 923-930. [CrossRef] [PubMed]

42. Robinson, M.D.; McCarthy, D.J.; Smyth, G.K. edgeR: A Bioconductor package for differential expression analysis of digital gene expression data. Bioinformatics 2010, 26, 139-140. [CrossRef] [PubMed]

43. Ramírez, F.; Ryan, D.P.; Grüning, B.; Bhardwaj, V.; Kilpert, F.; Richter, A.S.; Heyne, S.; Dündar, F.; Manke, T. deepTools2: A next generation web server for deep-sequencing data analysis. Nucleic Acids Res. 2016, 44, W160-W165. [CrossRef]

44. Lorenz, R.; Bernhart, S.H.; Zu Siederdissen, C.H.; Tafer, H.; Flamm, C.; Stadler, P.F.; Hofacker, I.L. ViennaRNA Package 2.0. Algorithms Mol. Biol. 2011, 6, 1-14. [CrossRef] [PubMed]

45. Darty, K.; Denise, A.; Ponty, Y. VARNA: Interactive drawing and editing of the RNA secondary structure. Bioinformatics 2009, 25, 1974. [CrossRef] [PubMed] 